\title{
A REALIDADE DA EDUCAÇÃO EM MINAS GERAIS
}

WALFRIDOS. DOS MARES GUIA NETO *

Foi-nos solicitado falar sobre a realidade da escola pública de Minas Gerais. Como não queremos nos limitar a citar estatísticas que demonstram o descaso a que foi relegada a educação ao longo dos últimos vinte ou trinta anos em nosso Estado e em nosso País, mencionaremos apenas alguns indicadores que caracterizam e dimensionam os problemas educacionais que estamos enfrentando. Estamos certos de que, à medida que formos falando, o auditório terá inúmeras contribuições a fazer, pois quem trabalha na área da educação se apaixona. **

O nosso primeiro desafio como Secretário da Educação foi organizar um plano de ação completo, coerente, com princípio, meio e fim, e que agora submetemos à apreciação dos senhores para que seja criticado e, a partir dessas críticas, melhorado. Mas antes, gostariamos de levar aos senhores uma idéia da dimensão dos problemas que afligem a educação em Minas Gerais.

A escola pública em Minas Gerais - federal, estadual e municipal - atende a 3,4 milhões de alunos do pré-escolar, do primeiro e do segundo graus, e a rede privada outros 400 mil alunos, totalizando 3,8 milhões de matrículas. $\mathrm{Na}$ faixa etária de sete a quatorze anos, correspondente ao primeiro grau - que é a prioridade estabelecida pela Constituição - temos uma população alvo estima-

* Secretário da Educaçảo do Estado de Minas Gerais, no Govemo Hélio de Carvaltho Gancia

** Palestra proferida na Assembléia Legislativa do Estado de Minas Gerais, em 1991. 
da em 3.050.000 crianças das quais 2.700 .000 estão matriculadas. Cerca de $10 \%$, portanto, estão fora do atendimento. Esse é um indicador favorável pois mostra que, de cada dez alunos do primeiro grau, nove estão freqüentando a escola. Não podemos, entretanto, nos iludir com essa estatística porque ela não nos fala sobre a qualidade do ensino oferecido aos que estão na escola e sobre o rendimento dos alunos.

Na faixa da pré-escola, os números do déficit escolar são impressionantes. A população alvo é de 1.153 .000 crianças e apenas 346.000 estão sendo atendidas. Temos aqui um problema sério pois $70 \%$ das crianças estão excluídas da pré-escola. De cada dez crianças de quatro a seis anos, sete estão fora da escola.

Os números do segundo grau são também alarmantes. E o problema se agrava quando consideramos as centenas de milhares de estudantes maiores de quinze anos matriculados no primeiro grau.

Temos na faixa etária de quinze a dezenove anos 1.861 .000 jovens que constituem a população alvo de segundo grau. As redes pública e particular atendem a apenas 230.000 . Cerca de $88 \%$ dos jovens nessa faixa etária estão, portanto, fora da escola de segundo grau. Os milhares de alunos entre quinze e dezenove anos ainda no primeiro grau atestam a baixa produtividade do Sistema, que vem se mostrando incapaz de mantê-los nas séries apropriadas à sua faixa etária.

A baixa produtividade e o grande número de jovens fora da sala de aula recomendam que o governo dê prioridade à melhoria da qualidade do ensino básico, que vai do pré-escolar ao segundo grau.

A rede pública estadual é gigantesca. Os alunos do ensino básico totalizam 2,7 milhões de estudantes distribuidos em 6.500 escolas servidas por 204 mil professores e funcionários. Esse sistema é inadministrável tal como o encontramos. Não se conhece no planeta nenhuma experiência de administração bem sucedida de um sistema dessa dimensão e com tal grau de centralização.

Portanto, a solução para o problema de gerir esse Sistema requer a sua descentralização, devolvendo as decisões para a escola, de onde elas nunca deveriam ter saído.

A imensa maioria dos problemas do nosso dia-a-dia não são resolvidos em benefício do aluno, a razão de ser da educação; ou em benefício do professor, o agente fundamental da educação; ou em favor da escola, o espaço educativo onde os fatos acontecem. O próprio conceito de escola tem que ser rediscutido, tamanho o desrespeito a que essa instituição foi submetida durante os últimos anos.

\section{Compromissos}

Estanos absolutamente convencidos de que, para resolvermos o problema da baixa qualidade do ensino oferecido pelas escolas públicas estaduais, te- 
remos que descentralizar rapidamente o Sistema, o que significa perda de poder pelo órgão central, constituído pela Secretaria da Educação e pelas Delegacias de Ensino, e transferência de decisões para a escola.

Para que tal reorganização do Sistema não seja feita de forma atabalhoada, procuramos contar desde o início com um grupo de pessoas capazes, compromissadas com a educação e que militam na área há anos. A primeira missão desse grupo foi a identificação de prioridades de ação pois não queriamos correr o risco de dar igual atenção a todas as questões e, no final desta administração, chegar à conclusão de que fizemos um pouco de tudo mas falhamos na solução das questões mais relevantes. Para näo reinventarmos a roda, tivemos o cuidado de ouvir e dialogar com os especialistas mais renomados do País. Traçamos então um plano de ação, em que estão claras as nossas prioridades. Vamos medir periodicamente os resultados para verificar se estamos tendo ou não sucesso nesta missão.

Os principais agentes da educação são: em primeiro lugar, o aluno; em segundo lugar, os pais do aluno; em terceiro lugar, o profissional da educação, ou seja, todas as pessoas que trabalham na escola - o professor, o especialista, o funcionário, o serviçal, a direção, bem como o inspetor que leva as diretrizes da Secretaria até a escola; e em quarto lugar, a escola.

Estamos assumindo com esses quatro agentes da educação os compromissos estabelecidos pela Constituição, que propōe um sistema de gestão democrático e participativo. Se já tivéssemos cumprido apenas as exigências da Constituição, sem nenhum rasgo de inteligência ou de inovação, as condições do ensino no Brasil seriam completamente diferentes das atuais. Basta dizer para nos limitarmos aos últimos cinqüenta anos - que a Constituição de 1946 já afirmava ser obrigação da União, Estados e Municípios oferecer escola pública universal e gratuita para todas as crianças de sete a dez anos - o antigo curso primário. Passados 45 anos, os que detiveram o poder ou tiveram condições de influenciá-lo, quaisquer que sejam os nomes que lhes queiramos dar - governantes, elites, formadores de opinião ou críticos - não tiveram motivação ou competência para organizar um sistema capaz de oferecer aos brasileiros ensino de qualidade. A maior prova desta afirmação são os milhões de analfabetos no País.

\section{Compromissos com o aluno}

A luta em favor da educação nos últimos cinqüenta anos - se ficarmos apenas neles - não foi suficiente para liberar a atual geração de educadores e de dirigentes da herança educacional caracterizada pela baixa qualidade do ensino. Dissemos que $90 \%$ das crianças na faixa etária do primeiro grau estão matriculadas; mas desses $90 \%$, somente $18 \%$ concluem o primeiro grau. Vale dizer que, de cada 100 alunos que ingressam na escola, somente 18 conseguem o 
diploma de primeiro grau. Os outros 82 alunos se perdem pelo caminho e ficam à margem do sistema educacional $\mathrm{e}$, às vezes, da sociedade.

A cada dia que passa, a situação se agrava, como ressaltou o Senador Fernando Henrique Cardoso. O Senador chamou a nossa atenção para a nova realidade do mercado de trabalho em que a mão-de-obra desqualificada tende a ser abandonada pela sua incapacidade de conviver com os métodos e técnicas mais modernos de produção. Essa constatação põe por terra o mito das décadas de 1950 e 1960 de que mão-de-obra e matéria-prima baratas seriam suficientes para promover o desenvolvimento do País. Muitos não se aperceberam de que havia uma nova variável chamada desenvolvimento científico-tecnológico que acabou jogando por terra aquele modelo como uma grande falácia.

As sociedades do terceiro mundo que se mostraram capazes de perceber a crescente importância do conhecimento científico e tecnológico e por isto investiram maciçamente em educação - os chamados tigres asiáticos - estão hoje sendo recompensadas com o ingresso no primeiro mundo. Infelizmente, năo foi o nosso caso. Mas podemos reverter esse quadro.

Como dissemos, não precisaremos ir além dos compromissos estabelecidos pela Constituição. O primeiro deles é o de garantir vaga ao aluno. Garantida a vaga, temos que assegurar a sua permanência na escola pelo menos por oito anos: esse é o imperativo constitucional de permanência do aluno na escola.

Garantir vaga é muito fácil. Basta construir prédios. Temos recursos para isso. Mas manter o aluno na sala de aula, ensiná-lo durante oito anos a ler, escrever, fazer contas, pensar, analisar, criticar, conhecer a Geografia e a História do Brasil e compreender a relevância do desenvolvimento científico e tecnológico para qualquer sociedade do terceiro milênio é o nosso grande desafio e é o papel da escola. É esse conhecimento que vai propiciar ao aluno tornar-se um cidadão capaz de fazer escolhas, conhecer opções e almejar responsavelmente uma vida social e economicamente digna.

Os nossos educadores devem, portanto, estar conscientes do seu papel de ensinar. Devem ter sempre em mente que os jovens vão à escola para aprender. Eque absorvem os valores do professor que os ensina. O professor tem portanto a obrigação de ajudar o estudante a adquirir senso crítico para a questão dos valores, pois é assim que ele se educará e aprenderá a tomar consciência de si.

O compromisso da vaga e da pernanência do aluno na escola demandarão um grande esforço dos mineiros em função do tamanho do Sistema. Mas temos ainda outros compromissos constitucionais. Para se tornar um sujeito crítico, o aluno tem que ser submetido a um currículo constituído de conteúdos programáticos de várias disciplinas. É preciso que esse currículo tenha algo a ver com a sua vida e não apenas com uma teoria que pouco se relaciona com a sua realidade. 
A Constituição garante ainda ao aluno alimentação, material escolar e assistência especial se for portador de deficiência.

Apenas para cumprir a Constituição será necessário que trabalhemos quatro anos com a maior dedicação. Portanto, a solução desses primeiros problemas essenciais - a garantia da vaga, a permanência na escola, o currículo e o programa, a alimentação e o material escolar, e a questão do portador de deficiência - previstos na Constituição, já compõem um grande desafio. As estatísticas indicam a existência no Estado de 280 mil crianças e jovens portadores de deficiência que esperam a nossa atenção pois assistimos apenas 30 mil deles ou $12 \%$ do total.

\section{Compromissos com os pais}

Todavia, há ainda outras obrigações como a de informar os pais a respeito do desenvolvimento de seus filhos dentro da escola. Poucos sabem que esse é um direito constitucional dos pais. A escola precisa respeitar a familia do aluno para que seja respeitada por ela.

Temos também que criar mecanismos que permitam cobrar dos pais o seu dever de participar da vida escolar. A própria Constituição enfatiza que a educação é um direito de todos, dever do Estado, da familia e que se desenvolverá com pleno apoio da sociedade. Então, a educação não é um dever apenas do Estado.

E como ficam os filhos de famílias carentes, muitas vezes completamente desestruturadas, e que mal conseguem sobreviver? Diante de famílias sem condições de cumprir a sua parte, cresce a nossa responsabilidade com a formação de indivíduos socialmente ajustados e integrados. Entretanto, precisamos criar dentro da escola ambiente para que a familia, por mais humilde e simples que seja, participe da vida escolar, até mesmo para que os pais se eduquem como cidadãos.

\section{Compromissos com os professores}

Temos, também, que pensar nos compromissos com os professores, os agentes do aprendizado. E preciso dar-lhes condiçōes adequadas de trabalhoe, muito mais do que isso, dar-lhes uma motivação para o trabalho. Esses compromissos significam a convergência na escola de vários fatores como condiçōes físicas adequadas de trabalho, salário digno, plano de carreira e incentivos para crescimento intelectual.

Não adianta repetir que, se aumentarmos apenas o salário, as coisas permanecem como estão. Se fizermos um plano de carreira, sem organizar o salário, as coisas também continuam como estão; se não adaptarmos a escola para que os professores tenham condições adequadas de trabalho, as coisas nova- 
mente permanecem como estão. As mudanças tềm que ocorrer de forma coordenada e simultânea. É preciso lutar por melhores salários e por tudo mais.

Como a rede estadual de ensino é grande demais, torna-se difícil promover tais mudanças a curto prazo. Mas não é difícil implementá-las de uma maneira organizada em um prazo pré-determinado; é o que nos propomos fazer.

O maior compromisso que assumimos com o professor é o de lhe propiciar uma carreira, para que possa se desenvolver profissionalmente e ter motivação para o trabalho. Esse compromisso, repito, será cumprido embora o Estado não saiba ainda como fazê-lo porque nunca o fez nos últimos trinta anos. O que existe hoje é uma pseudo-carreira. O professor progride apenas por estar trabalhando, por estar vivo, sem precisar desenvolver qualquer esforço intelectual. Hoje, ele inicia com um salário " $\mathrm{X}$ " e aposenta-se com um salário " $3 \mathrm{X}$ ", simplesmente pelo fato de continuar vivo, por conta dos biênios, qüinqüênios, progressão horizontal e gratificação trintenária. Para os que se aprimoram intelectualmente - exceções a essa regra geral - existe o acesso a niveis mais altos; de professor das quatro primeiras séries a professor de quinta a oitava séries e a professor do segundo grau.

O sistema é hoje tão mal administrado e incompetente que nem esses direitos, que estão na lei, são recebidos imediatamente pelos professores. À medida que vencem os biênios e qüinqüênios, os professores têm que se empenhar para receber os aumentos correspondentes. Têm que fazer um requerimento quando tal concessão deveria ser automática pois não há nada mais fácil do que contar o tempo de um professor na sala de aula.

\section{Compromissos com a escola}

O nosso comprometimento com a escola é muito simples; os compromissos que estamos assumindo com os alunos, pais e profissionais da educação devem ser resolvidos dentro da própria escola. Assim, a escola deve ter autonomia para proceder desde a simples troca de um vidro quebrado até a substituição de um professor não aceito pelas famílias ou pela escola. A gestão do diaa-dia será completamente resolvida pela escola. Não podemos mais depender de decisões do Secretário da Educação ou do Senhor Governador para trocar um vidro quebrado ou para alugar uma sala de aula.

Em um sistema centralizado como o nosso nada pode ser resolvido com simplicidade, mesmo que contássemos com 723 Delegacias de Ensino, uma em cada cidade. A situação só se modificará quando esses problemas forem resolvidos pela própria escola.

Esclarecidos os compromissos com os agentes da educação - alunos, pais, profissionais da educação e escola - pudemos estabelecer as cinco grandes prioridades que nortearão os nossos trabalhos durante os quatro anos deste governo. 


\section{Prioridades}

As prioridades são: (1) autonomia da escola; (2) fortalecimento da direção da escola através da liderança da diretora e do colegiado; (3) programa de aperfeiçoamento e capacitação, com o treinamento de professores, especialistas e funcionários; (4) avaliação do Sistema Estadual de Educação, prevista pela Constituição; (5) integração com os municípios. Veremos como essas cinco prioridades asseguram o cumprimento dos compromissos a que nos referimos.

\section{Autonomia da escola}

Em nosso modelo, a escola se agiganta como centro de decisões enquanto as Delegacias de Ensino e a Secretaria da Educação redefinem seus papéis e competências. A escola passa a ser o centro da questão educacional.

Autonomia significa que a escola assume uma nova gama de responsabilidades. Assume a responsabilidade de resolver os seus problemas. Para tanto, ela passa a contar com autonomia administrativa, financeira e pedagógica. Quando falamos "escola", estamos nos referindo às pessoas que nela trabalham, aos pais e aos alunos.

\section{Autonomia financeira}

A autonomia financeira é a mais fácil de ser conquistada ou praticada, bastando para isso vontade política. Se o governo quiser repassar o recurso para a escola, ele o repassa. Hoje, passados sete meses desde que assumimos a Secretaria, pioneiramente, já repassamos para as escolas de primeiro grau $\mathrm{Cr} \$ 6$ bilhões para custeio, isto é, para as despesas do dia-a-dia da escola.

Queremos mudar algumas regulamentações para que as diretoras façam com esse dinheiro o que bem entenderem, desde que obtenham a aprovação do Colegiado. Ao receber um recurso, a diretora fará um pequeno plano de aplicação. Caso ela pretenda comprar uma televisão ou pintar a fachada da escola deverá submeter previamente esses gastos ao Colegiado. O Colegiado deverá aprovar o seu plano de aplicação, seja ele de $300 \mathrm{mil}$ ou de 3 milhões. Esse plano, que pode ser analisado em uma reunião de duas horas, dirá como a diretora irá gastar o dinheiro. Aplicado esse dinheiro, o mesmo Colegiado aprovará as contas, conferindo os recibos e os gastos e fazendo uma ata que será enviada diretamente para o Tribunal de Contas, sem passar pela Delegacia ou pela Secretaria.

Não seremos fiscais de escolas que pretendemos autônomas. Não lhes diremos como gastar os recursos recebidos. Temos certeza de que a escola saberá utilizá-los melhor do que a Secretaria da Educação ou as Delegacias de En- 
sino porque estamos muito afastados dos problemas que ela enfrenta em seu dia-a-dia. Sabemos que a comunidade escolar, formada de pais, alunos, professores e funcionários da escola, tem muito a nos ensinar. $\mathbf{O}$ envolvimento dos pais é fundamental pois qualquer pessoa, por mais despreparada que seja, não irá prejudicar o seu filho em favor de outros objetivos.

A participação do Colegiado é essencial. Sem ele, tudo de que estamos falando perde a sua razão de ser; ele é a comunidade dentro da escola. Por isso respeitamos o esforço feito em administrações anteriores para criá-los em todas as escolas. $O$ Colegiado não precisa ser formado de trinta ou quarenta pessoas. Estamos pensando em, no máximo, doze membros.

Partimos do princípio de que as transformações que estamos promovendo são irreversíveis. Não pretendemos garantí-las por decreto pois estamos cansados de ver leis revogadas ou simplesmente ignoradas. $O$ que garantirá a irreversibilidade das mudanças que estamos promovendo será a entrada definitiva da família na escola. Entendemos que após a sua entrada, ninguém mais conseguirá tirá-la.

A introdução da familia na escola demandará um certo tempo e muito trabalho. É um exercício cotidiano. É, porém, condição "sine qua non" para que qualquer estrutura educacional funcione, em qualquer parte do mundo. Apenas as sociedades em que a familia participa do processo oferecem educação de qualidade aos seus cidadãos. A escola funciona mal ou não funciona onde a familia está ausente, mesmo havendo recursos disponiveis.

A autonomia financeira está sendo implementada rapidamente. Nas negociações que fizemos no início do ano com o Sindicato, assumimos o compromisso de transformar em lei os critérios de transferência de recursos para a escola. Assumimos pessoalmente o compromisso de criar um instrumento legal que garantisse a transferência automática de verbas para a escola até o meio do próximo ano, de forma a assegurar que ern futuras administrações tais transferências ocorrerão independentemente da boa vontade de quem esteja no comando do Sistema. No momento, estamos estudando a melhor maneira de realizar tais transferências.

Queremos que o montante de recursos canalizado para a escola seja calculado levando-se em consideração, além do número de alunos, alguns indicadores sócio-econômicos das carências regionajs, e a qualidade da administração da escola, privilegiando as escolas que precisam mais e que aplicam melhor os recursos recebidos. Não queremos adotar uma distribuição linear proporcional ao número de alunos, como fizemos ao destinar 2 mil cruzeiros por aluno para as escolas beneficiadas com os Cr $\$ 6$ bilhões repassados este ano - valor superior ao orçamento de muitas de nossas Secretarias de Estado. Assim ofizemos porque não tinhamos este ano condições de proceder de melhor forma, pois os mecanismos de transferência não eram familiares à Secretaria. Se tais transferências ocorreram no passado, foram concedidas como benesse, resulta- 
do de decisões. Os repasses de verba não podem ser entendidos pela escola como favor e sim como um direito assegurado pela Constituição.

As escolas terão dotação anual. Os recursos correspondentes a essa dotação têm que ser transferidos com regularidade para que a escola possa programar a sua utilização. Caso contrário, teremos um movimento de vai-e-vem que inviabiliza qualquer planejamento. A escola não pode ter dúvidas quanto às datas em que os recursos irão chegar. Estamos convictos de que esses recursos irão chegar. Estamos convictos de que esses recursos podem seguir um fluxo previsivel porque são originários do salário-educação, que é atrecadado pelo governo federal mensalmente, e é intocável.

A autonomia financeira é a mais fácil de implementar. Temos a impressão de que dentro de um ano, no máximo, estaremos com toda ela regulamentada, fazendo parte da rotina da escola e da Secretaria.

A autonomia financeira não consiste apenas em receber o recurso, fazer um plano de aplicação através do Colegiado, gastá-lo, prestar contas ao Colegiado e mandar os relatórios para o Tribunal de Contas. Autonomia financeira também significa saber qual é o custo real da escola.

A educação não tem poder de barganha junto a esta Assembléia porque, apesar de a imensa maioria dos seus 77 deputados estar interessada em colaborar na solução dos problemas educacionais, a Secretaria da Educação não tem hoje condições de apresentar-lhes um orçamento fundamentado, consistente. $O$ nosso pleito tem se limitado a uma folha de pagamento a uma estimativa grosseira das despesas de custeio. Ora, se recursos para despesas de custeio e de pessoal são insuficientes para assegurar ensino de qualidade, estamos condenados, eternamente, a repetir resultados medíocres. Isso acontece porque nenhuma escola sabe qual é o seu custo, em quanto fica o pagamento dos salários de seus professores, qual o montante de suas despesas de custeio: água, luz, telefone, papel, lápis, etc. e quanto precisa para atender a outras necessidades, como, por exemplo, treinamento de seus professores.

Aprovamos até agora 1.300 convênios para reformas de prédio. São 1.300 escolas públicas, vergonhosamente depredadas, melhorando suas condições físicas. No entanto, poderiamos ter 2.500 e não as temos porque muitas vezes somos incapazes de preencher uma planilha corretamente, exigência do Tribunal de Contas para a celebração de um convênio. Até isso é um desafio para nós. Alguns deputados são testemunhas dessa realidade pois tivemos oportunidade de lhes mostrar o saldo do salário-educação para reformas.

Estamos solicitando a todos - prefeitos, delegados de ensino, líderes comunitários - que nos mandern a planilha de todas as escolas em más condições. Nosso Sistema ainda não está perfeito, mas, em breve, teremos condiçōes de receber as planilhas e, se os valores estiverem corretos, fazer o convênio para melhorar as instalações dessas escolas. 
A escola tem que saber o quanto custa. É preciso que ela conheça seus gastos mensais para que, ao final do ano, possa preparar o orçamento para o ano seguinte. Cada diretor terá um orçamento organizado de sua escola. E a soma dos orçamentos das 6.500 escolas será o orçamento da Secretaria da Educação. Cada município poderá saber quanto custam suas escolas públicas. Será então possível dirigir-se aos senhores deputados para negociar os recursos de que a escola realmente precisa para funcionar normalmente e oferecer ensino de qualidade.

Assim, o Sistema Estadual de ensino se encontra tão desorganizado e desprestigiado que não tem poder de barganha para lutar por mais recursos porque não é capaz de comprovar suas necessidades. Temos que partir para uma denúncia fundamentada, baseada em dados quantitativos, demonstrando com números a situação de calamidade das escolas e assim solicitar mais verbas para a educação. A recuperação do Sistema deve partir de dentro da escola. A nossa experiência mostra que o orçamento da escola pode ser feito por um funcionário que tenha segundo grau, com treinamento de doze horas.

O maior desembolso de uma escola é com o seu pessoal. O sistema de pessoal que estamos implantando será descentralizado. Numa folha de computador teremos a lista de todos os funcionários da escola com seus salários, dados pessoais, gratificações a que têm direito como biênios e qüinqüênios, a sua progressão horizontal, etc. A própria escola cuidará disso.

\section{Autonomia administrativa}

A autonomia administrativa é mais complexa do que a financeira. Contudo, sua implantação não é impossível. Acreditamos que até junho do próximo ano a teremos introduzido nas escolas.

O item mais difícil e desafiador da autonomia administrativa é a gerência de pessoal, assunto em que todos se intrometem. Em geral, as regras são boas, mas o próprio funcionário não respeita a legislação. Por exemplo: há $18 \mathrm{mil}$ pessoas pagas pela Secretaria da Educação que deveriam estar dentro da sala de aula, e não onde estão. Elas prendem uma vaga que é preenchida por um designado que não tem os mesmos direitos do efetivo ou do estável. Isso porém é apenas um detalhe. O próprio funcionário que trabalha no Sistema Educacional o vê tão desorganizado que trata de se ajeitar. E esse ajeitamento é feito através do clientelismo, sempre em prejuizo da escola.

Confessamos aqui - e fazemos questão de dizer isso - que achávamos que o clientelismo tinha origem no deputado. Mas reconhecemos que não é verdade. A causa principal do clientelismo é o funcionário que procura o deputado com uma história, freqüentemente duvidosa, para conseguir uma vantagem. Por isso estamos pedindo aos deputados - já conversamos com vários deles pessoalmente - para que nos ajudem. Eles nos entenderam e o número de pedi- 
dos de remoção e de disponibilidade, de junho para cá, caiu assustadoramente. Quando iniciamos na Secretaria, encontramos 6 mil pedidos de remoção. Ao examiná-los, vimos que não poderíamos atender nem a duzentos. A história é quase sempre a mesma: "passei no concurso mas estou morando em outra cidade". Na verdade, quando fez o concurso já morava em outra cidade. Outros pensam: "estou há cinco anos na sala de aula; está na hora de sair pois não agüento mais." Esse sistema é inadministrável. Podem colocar um gênio na Secretaria que ele não conseguirá gerir o sistema atual. Temos a regras. Todos sabem quando uma pessoa tem direito à remoção de uma escola; entretanto, recebemos centenas de pedidos de exceção que não podemos atender porque ferem a legislação.

O Sistema, tal como existe hoje, é atrasado e só leva ao retrocesso, dificultando, em nossa opinião, o desempenho da maioria dos deputados, que poderiam estar usando a sua inteligência e a sua experiência na defesa de causas mais nobres da educação. Gostaríamos de ilustrar a nossa fala com um exemplo. Um prefeito nos procurou seis vezes para pedir a adjunção de sua filha durante o estágio probatório. Mostramos que a lei é clara: durante o estágio probatório o funcionário não pode ser removido, com uma única exceção que não era o caso. Ele insistiu: "Senhor Secretário, dê um jeito nisso". Ao negar tais pedidos, podemos estar criando problemas "políticos" mas estamos agindo de forma consciente e temos certeza de que, com o passar do tempo, a grande maioria, inclusive aquele prefeito, nos apoiará. É preciso ir ao nosso gabinete para ver os absurdos que chegam. Às vezes, os pedidos são escritos. Temos de responder a todos eles e com isso perdemos tempo.

Vamos acabar com esses pedidos através da autonomia da escola. Se o professor quiser sair da escola, deverá preencher uma ficha e entregá-la à diretoria, que reunirá o Colegiado e examinará o pedido. É fundamental que o Colegiado participe desse processo porque, quando as remoções tiverem que ser por ele aprovadas, em vez de seis mil pedidos, teremos apenas sessenta. A escola estudará o mérito do pedido e, caso ele esteja dentro da lei, o Colegiado passará a examinar o interesse do aluno, o que nunca é feito. O que não pode continuar acontecendo é a saída de professores das escolas, deixando os alunos sem aulas, com a diretora tomando conhecimento do fato através do "Minas Gerais". É então convocada, às pressas, uma substituta e está instalado o caos naquela sala de aula.

Um pai, em Muriaé, nos relatou que sua filha teve sete professores apenas neste ano. Ora, não há sistema escolar que resista a uma desorganização dessa natureza, em nenhum lugar do mundo. Isso acontece porque a prioridade não é o aluno e sim o funcionário. Temos que equilibrar os interesses do aluno com os do professor, através da escola.

A administração de recursos hurnanos gera muitos problemas porque os cálculos de muitos benefícios são feitos de forma ineficiente pelas Delegacias. 
A centralização da concessão desses benefícios nas Delegacias cria um clima de insatisfação nos funcionários das escolas que muitas vezes não recebem em dia as vantagens que a lei lhes garante. Chegam a receber os próprios salários com quatro ou cinco meses de atraso. O Sindicato tem feito denúncias a esse respeito e nós, pessoalmente, já trabalhamos horas a fio em cima desse assunto. Mas, nas condições de hoje, não foi ainda possivel resolver esse problema. A solução definitiva virá naturalmente quando essas decisões forem tomadas na própria escola.

Com a autonomia da escola, a professora que constatar alguma irregularidade em seu contra-cheque terá o problema sanado na escola pela diretora. A assinatura da diretora será o aval de uma autoridade escolhida em função de uma prova e de uma avaliação pela comunidade, dispondo, portanto, de fé pública. A escola passará, então, a contar com um poder de decisão que dela nunca deveria ter saído.

Estamos falando por meia hora e somente fizemos referência a entraves à administração da educação que estão na esfera do próprio Estado de Minas Gerais, sem qualquer envolvimento do Governo Federal. Trata-se portanto de problemas que cabe a nós resolver.

Esperamos que até o final do próximo ano as escolas sejam capazes de administrar os seus recursos humanos, organizar a vida dos seus professores garantindo-lhes automaticamente as vantagens expressas em lei como o biênio, o qüinqüênio e a progressão horizontal. Assim os funcionários da educação terão seus direitos garantidos, sem necessidade de pedir, sem serem destratados como muitas vezes acontece nos guichês das grandes Delegacias de Ensino. Infelizmente, há em enorme aparato burocrático que nada resolve, um problema que tivemos oportunidade de constatar "in loco". Vamos acabar com a burocracia da Secretaria e das Delegacias, dando às escolas poder e competência para solucionar os problemas de seus professores.

Em vez de a Delegacia de Ensino manter $6 \mathrm{mil}$ pastas relativas a $6 \mathrm{mil}$ professores, a escola terá trinta pastas de trinta professores. Uma única pessoa será capaz de cuidar bem desses documentos. Se o professor mudar de escola, leva consigo a sua pasta; é a sua vida. Ele a entrega para nova escola e começa mais uma etapa. Se o professor tiver dojs empregos no Sistema, a pasta ficará na escola em que ele desenvolve maior atividade. E uma escola fornece informações para a outra, como vasos comunicantes. Não precisamos dessa burocracia que emperra o Sistema.

Falamos em autonomia administrativa, limitando-nos à questão do pessoal. Antes de passar à autonomia pedagógica, desejamos ressaltar que a conservação e a melhoria dos prédios vão ser feitas pela própria escola. Ela terá recurso para "se consertar" quando houver algum problema de manutenção. Esses recursos serão repassados para a escola via convênio com a caixa escolar ou 
com a prefeitura, conforme a prioridade "cinco" que prevê uma maior integração com os municípios.

\section{Autonomia pedagógica}

A autonomia pedagógica é o nosso grande desafio, porque a escola tem que conhecer a sua razão de ser, o que pretende fazer, a sua opção de como atuar. Implicitamente, a escola tem consciência dos seus objetivos mas normalmente tem dificuldades em explicitá-los. A simples interação da escola com a comunidade, buscando identificar com clareza a sua missão, já é capaz de mudar o clima dentro dela. A partir das discussões sobre o papel da escola, as pessoas passarão a se sentir mais motivadas, a entender por que vale a pena esforçar-se para que a escola funcione bem. E perceberão que não vale a pena deixar que os problemas se compliquem antes de serem resolvidos.

A autonomia pedagógica tem que ser conquistada pela escola. Nãoé possivel garantir apenas com mudanças estruturais - descentralização e reorganização - a conquista dessa autonomia. Entre inspetoras, delegadas de ensino, diretoras da secretaria e superintendentes, temos 1.100 pessoas. $O$ grande trabalho que esses profissionais irão realizar é o de ajudar a escola a conquistar a sua autonomia. Não é preciso nem se preocupar com a fiscalização do ponto de vista financeiro porque esse trabalho será feito pelo Tribunal de Contas. Com relação à parte administrativa, as inspetoras têm um conhecimento muito valioso e podem ajudar a dirimir dúvidas.

Procuraremos melhorar a comunicação interna do Sistema Estadual de Ensino. Porém, dado o gigantismo do Sistema, as cifras são sempre enormes. A instalação de um centro telefônico em todas as escolas de Minas Gerais custa $\mathrm{Cr} \$ 3,2$ bilhões. O telefone é mais caro do que o computador. Mas vamos instalar os dois.

O Sistema Educacional vai ter que funcionar desde o nosso Gabinete até a sala das escolas mais longínquas, com a cooperação das inspetoras. Teremos que aprender a trabalhar de forma coordenada para auxiliar as escolas a conquistar a sua autonomia. Em vez de ficarmos presos aos aspectos formais da Lei $n^{\circ}$ 5.692 e às resoluções do Conselho Estadual de Educação, temos que nos reunir dentro da própria escola com toda a comunidade escolar: professores, funcionários, especialistas e pais. Devemos conversar com eles para saber o que está acontecendo, quais são as dificuldades e os problemas que estão vivendo. Precisamos motivar os pais a trabalhar pela melhoria da escola pública mostrando que eles podem contribuir com pequenas providências que, somadas, farão uma grande diferença, desde que sejam convergentes e sistemáticas.

$O$ trabalho fundamental das quarenta e duas delegacias será o de fomentar a autonomia das escolas, sobretudo a autonomia pedagógica. As escölas deverão trabalhar os seus programas e currículos. Nesse campo, o espaço para a criatividade é total. Mas isso é uma conquista a ser feita com responsabilidade 
e competência pelos que dirigem a escola e por toda a comunidade escolar. Não se faz autonomia pedagógica apenas com boas intenções. É preciso um projeto escrito, fundamentado. A elaboração de um projeto pedagógicoé uma tarefa difícil, mas essa é a verdadeira missão da escola.

\section{Fortalecimento da direção da escola}

Falamos sobre a autonomia da escola, que é o cerne do nosso plano de ação. Agora abordaremos o fortalecimento da direção da escola, a prioridade número "dois". Prestem atenção ao termo: não é fortalecimento da diretora e sim da direção da escola. A direção da escola compreende a diretora mais o Colegiado. A liderança da diretora contará com o apoio do Colegiado.

É muito importante que todos entendam que não queremos uma diretora "forte" para que saia dando ordens. O nosso objetivo é exatamente o contrário. A nova diretora será suficientemente forte para não precisar "mandar". Poderá, assim, permitir que competências floreçam ao seu redor. A nova diretora, legitimada pelo mérito demonstrado na prova realizada em 13 de outubro e aceita pela comunidade através da votação de 24 de novembro, estará preparada para liderar a escola e não para mandar na escola. Fazemos esta afirmação com bastante clareza porque a época da gestão "do mandar", do "autoritarismo" voltado para publicação de portarias dizendo "cumpra-se", já passou. "Mandonismo" é sintoma de atraso. Nenhuma hierarquia, hoje, é dirigida na base do "cumpra-se".

Ternos que aprender a criar um ambiente de participação na escola. Professores, funcionários, pais e alunos têm que se sentir parte de um todo com o qual estejam comprometidos. Se não for assim, não há mágico capaz de melhorar o ensino. A boa diretora é aquela que aparece pouco e faz as pessoas aparecerem muito. Ela tem que ser suficientemente forte para não ter receio de parecer fraca diante da força das pessoas que estarão à sua volta representando a comunidade escolar. Não terá que explicar como foi escolhida diretora porque seus direitos foram conquistados. Na medida que ela se fez diretora por seus próprios méritos - e a comunidade escolar a legitimou - ela poderá cobrar apoio da comunidade, assim como a comunidade poderá reclamar de posturas e decisões que reflitam uma mentalidade autoritária e arbitrária.

O professor Jamil Cury falou brilhantemente, em Brasília, no Plenário do Conselho dos Secretários Estaduais de Educação, que o excesso de consultas e de "democratite" é uma decorrência do autoritarismo de trinta anos. Queremos que o getenciamento da escola seja feito de forma simples, objetiva e clara. Queremos que a nova diretora, qualificada, crie condições para que as pessoas participem das decisōes, mas sem recorrer a uma votação a cada minuto. Basta que ela tenha um sistema de consultas organizado e saiba ouvir alunos e profes- 
sores. Porém, esse "ouvir" não é juntar todas as pessoas a cada momento para uma reunião.

Para as decisões mais difíceis existe o Colegiado, também eleito, composto de representantes de pais, alunos, professores e funcionários. Estamos seguros de que, à medida que o Colegiado trabalhe com a direção da escola de modo eficaz e comprometido, a diretora irá errar menos. Ela vai mandar menos, vai ser menos autoritária e vai dar mais oportunidades para as pessoas opinarem. A organização de um sistema de tomada de decisões mais simples permitirá uma participação mais ampla de pais e funcionários. Quem já fez esse trabalho conhece a energia que existe nas pessoas e que pode ser liberada e canalizada para a melhoria do ensino. A escola melhora em relação a si mesma. Todos identificarão as falhas e os problemas das escolas e do Sistema e irão cooperar para solucioná-los.

A liderança da diretora tem que ser aprendida pois ninguém antes a ensinou a trabalhar com autonomia, entrosada com a comunidade. Vamos fazer um plano de treinamento competente para que ela possa dar conta do recado. Estamos pedindo a quem tem experiência que nos ajude a organizar um plano eficaz e de alto nível para treinamento gerencial das novas diretoras. É fundamental a liderança da diretora, apoiada pelo colegiado, na criação de um ambiente propício à participação de todos.

Queremos ressaltar que a forma de administração proposta não tem nada a ver com a co-gestão. Trata-se de uma gestão em que a diretora é a autoridade responsável. Ela assumirá a responsabilidade pelas decisões nesse gerenciamento participativo. OColegiado irá apoiá-la nas decisóes mais essenciais: planejamento dos investimentos, fiscalização dos gastos, gerenciamento e movimentação de recursos humanos, avaliação do Sistema, participação nas discussões sobre a melhoria pedagógica da escola.

O Colegiado ajudará a diretora - sem ser indelicado com ninguém e sem lançar mão de medidas autoritárias - a evitar impropriedade como os atestados médicos falsos, as ausências provocadas por doenças que não são doenças. Os funcionários do Sistema que recorrem a tais expedientes prejudicam aqueles que realmente estão enfermos e que muitas vezes precisam de um apoio que não estão recebendo. Esses abusos deixarão de existir quando o Colegiado assumir a atitude de ajudar aqueles que de fato estão doentes.

Se o funcionário que não puder trabalhar receber a visita de solidariedade de um membro do Colegiado, mereceremos o seu reconhecimento e acabaremos com os casos de falsos atestados médicos. Não conhecemos as estatísticas sobre o assunto, mas todos nós sabemos da enorme quantidade de abusos e de absurdos. E nada acontece. Em vez de ficarmos apenas lamentando e criticando, vamos sugerir medidas práticas e simples como esta da visita ao doente. $O$ funcionário que adoece recebe a visita do membro do Colegiado que more mais próximo. E esse membro leva o apoio dos colegas para o enfermo que, às vezes, 
não tem dinheiro nem para comprar o remédio de que precisa. E com essa ação de solidariedade, o Colegiado também inibe os aproveitadores.

Sintetizando, a primeira prioridade é a autonomia da escola nos seus aspectos financeiros, administrativos e pedagógicos; a segunda, o fortalecimento da direção da escola através da liderança da diretora e do Colegiado; a terceira, a capacitação, o treinamento de professores; a quarta, a avaliação do Sistema; a quinta, a integração com os municípios.

\section{Aperfeiçoamento e capacitação de professores}

O treinamento dos professores é o nosso maior desafio. Faremos um pequeno exercício para que os senhores possam ver a dimensão desse problema através da quantificação dos recursos e do esforço gerencial que ele requer.

Temos 125 mil professores dentro da sala de aula. Desses 125 mil professores, 4.730 , no primeiro grau, não têm o curso de magistério. Dos 4.730 que não têm curso de magistério, 3.199 não têm o segundo grau. Desses 3.199, quatrocentos não têm nem mesmo as quatro primeiras séries do primeiro grau e estão dando aula para os nossos alunos.

Os 4.730 professores sem o curso de magistério estão identificados em cada escola, em cada Delegacia, em cada núcleo. Agimos imediatamente para habilitá-los, mas isso leva tempo, a menos que os tiremos da sala de aula para treiná-los em tempo integral.

Dos professores de segundo grau, 11.602 não têm o curso superior. Não estou falando como denúncia, mas simplesmente constatando um fato que nos desfia: 11.602 professores estão dando aulas da quinta série em diante sem terem curso superior. Têm apenas o segundo grau completo, ou nem isso.

Está entre os presentes o Professor Pompeu, diretor da Faculdade de Educação. Gostariamos que a Faculdade de Educação, se possível, assumisse os 11.602 professores para transformá-los em professores qualificados, em três anos. Sabemos que é uma tarefa gigantesca treinar mil pessoas e imaginamos o que seja treinar 11.000. Na verdade, estamos falando de 11.602 professores sem curso superior lecionando para o segundo grau acrescidos dos $4.730 \mathrm{sem}$ o curso de magistério, perfazendo um total de 16.332 pessoas.

Portanto, 16.332 ou $12 \%$ dos professores do Sistema não têm habilitação mínima para exercer sua função, independente de qualquer avaliação de mérito. Não estão incluídos nessa estatística os advogados, os engenheiros, os bioquímicos e os médicos que estão dando aula de Física, Matemática e Português e que têm curso superior. Além desses 16 mil, temos os outros 109 mil para serem treinados.

Às vezes, alguém nos diz que irá fazer um plano de treinamento. Perguntamos: para quantos? Respondem: para 40. Dizemos: Ótimo, mas estão faltando 124.960 para serem treinados. E como fazer isso? Olhem a dificuldade. Mas 
não estamos dizendo que seja impossível. É possível até que o possamos fazer depressa, em três, quatro anos. O treinamento de professores é o maior desafio que encontramos, maior do que a própria autonomia da escola, mas vamos enfrentá-lo e vencê-lo.

Vamos dimensionar o problema do treinamento imaginando um programa de reciclagem para todos os 125 mil professores durante os anos de 1992 , 1993 e 1994. A cada ano proporcionaríamos a 1/3 de todos os professores, ou 42 mil professores por ano, um mínimo de 80 horas-aula. Se treinássemos esses 42 mil em tempo integral, durante um mês, quatro horas pela manhã ou quatro horas à tarde, teriamos sempre 3.500 professores em treinamento. Se dividíssemos os 3.500 professores em turmas iguais de vinte, teríamos, sistematicamente, 175 turmas por mês. Isso custa aproximadamente doze milhões de dólares por ano. Teremos esse dinheiro. $O$ que não temos são mecanismos gerenciais para treinar $10 \%$ dos 125 mil professores. Teremos o dinheiro, mas não sabemos ainda como fazer. Por isso, temos que recorrer a todos que puderem nos ajudar.

Vamos ver por que tal treinamento custa 12 milhões de dólares por ano. Se oferecermos aos professores que ministrariam as 20 aulas semanais um milhão de cruzeiros por mês, estaremos pagando o melhor salário a um professor qualificado no Estado. Esses "professores de professores" custariam $\mathrm{Cr} \$ 175$ milhões por mês. Se tirarmos da sala de aula os 3.500 professores a serem treinados, pagando $\mathrm{Cr} \$ 150.000 .000$, em média, para o substituto, estaremos dispendendo por mês $\mathrm{Cr} \$ 525$ milhões. Considerando os demais custos de treinamento, chegaremos a um valor da ordem de $\mathrm{Cr} \$ 800$ milhões por mês ou $\mathrm{Cr} \$$ 9,6 bilhões por ano, equivalentes a US $\$ 12$ milhões anuais. Cr $\$ 9,6$ bilhões correspondem à terça parte dos recursos do salário-educação.

Não estamos dizendo que o treinamento será feito desta maneira. Estamos apenas fazendo um exercício para demonstrar que a nossa limitação em matéria de reciclagem e treinamento de pessoal não é o dinheiro mas sim a capacidade gerencial do Sistema.

Apresentamos ao Banco Mundial, no mês de fevereiro, um projeto de investimento em educação, quando o Governador eleito esteve nos Estados Unidos. $O$ Banco Mundial aceitou, em princípio, financiar o projeto e veio a Belo Horizonte para discuti-lo conosco. O principal item contemplado no projeto é o treinamento de professores. O financiamento do Banco Mundial deverá ser aprovado no decorrer de 1992, iniciando-se os desembolsos em 1993. Mas, em 1992, com o dinheiro do salário-educação, já poderemos começar o treinamento de professores porque não teremos tantas escolas a recuperar como neste ano.

Estamos solicitando ao Banco Mundial um empréstimo de 200 milhões de dólares para um programa de investimentos que se estenderá por dez anos, com desembolsos anuais da ordem de 20 milhões de dólares. Desse total anual, 
cerca de 10 milhões de dólares, ou 50\%, serão destinados ao treinamento de professores. Teremos, portanto, recursos suficientes para que, a cada três anos, todos os professores do Sistema possam se beneficiar de uma reciclagem de um mês, fora da sala de aula, com seu salário pago integralmente. $O$ treinamento de professores, tarefa desafiadora sob a perspectiva gerencial, é compatível com a disponibilidade de recursos para a educação.

$O$ aperfeiçoamento intelectual dos professores será um passo importante em direção à sua valorização profissional. A carreira do professor possibilitará outros treinamentos. Estamos negociando ainda com o Banco Mundial, na linha de desenvolvimento de pessoal, US\$10 milhões para o treinamento das diretoras. E estamos também negociando com aquela instituição US $\$ 50$ milhões para a construção de pré-escolas nos municípios que desejarem operá-las.

Dos 723 municípios mineiros, cerca de 300 não gastaram com educação os $25 \%$ previstos na Constituição. Concluímos que, em vez de ficarmos brigando com esses municípios, vamos motivá-los a investir em educação. Um caminho pode ser a pré-escola. Pretendemos colocar, pelo menos 500 mil crianças na pré-escola ao longo dos próximos seis a oito anos, em escolas municipais.

\section{Avaliação do sistema}

A quarta prioridade é a avaliação do Sistema. Para nos ensinar a avaliar o Sistema - o que ninguém tem sabido fazer nos últimos tempos - estamos contactando a Fundação Carlos Chagas. Dessa maneira, veremos se o Sistema melhora em relação a si mesmo. Essa será também uma forma de medirmos os resultados do nosso próprio trabalho.

A avaliação se fará de duas maneiras: (a) aplicaremos questionários nas escolas para conhecer a sua situação através dos professores e dos especialistas; (b) e em seguida mediremos o desempenho dos alunos. A avaliação dos alunos será realizada no mesmo dia e na mesma hora em todas as escolas do Sistema Estadual. Com esse teste poderemos comparar a performance de diferentes escolas, cidades e regiões. Poderemos então ajudar as escolas que necessitarem de auxílio. Estaremos também identificando as escolas de maior sucesso para levar a sua experiência às outras unidades de ensino. Pretendemos no futuro estender a avaliação externa às escolas municipais e particulares interessadas, de forma a poder comparar os sistemas estaduais, municipais e particular.

\section{Integração com os municípios}

A quinta prioridade se refere à integração do Estado com os Municípios. O Município, o Estado e a União são autônomos. A legislação federal tem que ser diretiva no que diz respeito ao Estado e o mesmo se aplica à legislação estadual no que se concerne ao Município. O Município tem que gastar $25 \%$ de seu orçamento com educação; o nosso Estadojá está gastando $32 \%$. Porém, se o Es- 
tado não gastar com competência e em sintonia com o Município, a nossa soma de dois mais um não dará três. Perderemos por falta de entrosamento.

O orçamento do Estado de Minas Gerais, apenas para a educação, é de cerca de US\$ 600 milhöes por ano, sem contar os recursos do salário-educaçăo. As prefeituras, apenas aplicando os $25 \%$ da receita fiscal, gastarão, pelo levantamento que fizemos junto à Secretaria de Planejamento, de US $\$ 220$ a $250 \mathrm{mi}$ lhões. Estamos portanto falando em US\$ 820 a US $\$ 850$ milhões, excluídos o salário-educação e outras contribuições que o próprio Sistema pode conseguir com o financiamento do Banco Mundial.

Então, se o Sistema Estadual possui 2,7 milhões de alunos e os Municipios somados 0,7 milhões, temos cerca de 3,4 milhões de alunos nas redes estadual e municipal em Minas Gerais. Estamos gastando, portanto, US\$240,00 por aluno, a cada ano, excluídos os recursos do salário-educação. Segundo o UNESCO, US $\$ 200,00$ é o patamar mínimo para se oferecer uma educação de razoável qualidade. Estamos ligeiramente acima desse patamar. Portanto, quanto aos recursos, não adianta reclamar pois eles estão ai, sendo gastos.

Algumas prefeituras estão realizando trabalhos admiráveis. A prefeitura de Varginha, por exemplo, está investindo $43 \%$ do seu orçamento bruto em educação; a Prefeitura de Contagem está gastando $40 \%$ pelo terceiro ano consecutivo; e a de Belo Horizonte está fazendo um grande trabalho. Depois de amanhã, a rede municipal de Belo Horizonte estará assumindo três escolas estaduais e vai contratar professores para essas três escolas municipalizadas. Estão aumentando consideravelmente o número de alunos e pagando razoavelmente bem aos professores, em relação à média nacional. A mestna atenção à educação está ocorrendo em muitas outras cidades que não citaremos para não cometer injustiças com aquelas cujos nomes poderemos esquecer.

Um problema sério que constatamos é a falta de identificação da imensa maioria dos prefeitos com a escola estadual. Eles enxergam uma separação entre as duas redes - rede municipal versus rede estadual. É quase uma competição. Vimos recentemente em uma cidade do Triângulo um prédio público municipal maravilhoso ao lado de uma escola estadual em condições lastimáveis. Com $10 \%$ do que foi gasto no prédio municipal teria sido possível colocar a escola estadual em condições iguais à municipal. Mas o raciocínio que prevaleceu foi o de que cuidar do segundo prédio é obrigação exclusiva do Estado, como se os alunos da escola estadual não morassem na mesma cidade.

Precisamos convencer os prefeitos a fazer mais, tanto pela rede municipal quanto pela estadual. Todavia, não faremos isso por decteto, com autoritarismo, e sim com esclarecimento e diálogo. Temos viajado muito pelas 36 associações microrregionais de municipios e ficamos entusiasmados com a receptividade que as nossas propostas estão tendo. Colocamo-nos às ordens dos prefeitos para, caso desejem, trabalharmos em parceria, ajudando-nos mutuamente. Eles vêm o que podem oferecer e nós o que podemos fazer para ajudá- 
los. Não pedimos nenhum comprometimento; propomos apenas um convênio denominado "guarda-chuva" que o prefeito assina, sem nenhuma obrigação e que the permite contabilizar todos os gastos realizados em escolas do Estado para efeito do cálculo dos $25 \%$ exigidos pela Constituição. Precisamos trabalhar juntos e se a comunidade participa, a escola estadual estará em melhores condições para cobrar apoio da prefeitura.

Um problema sério a ser resolvido é o recebimento incorreto do SalárioEducação pelo Estado. O Governo Federal deveria transferir o Salário-Educação para os estados em duodécimos, à medida que ele é recolhido, sem retê-lo. O Ministro da Educação se comprometeu conosco a tentar repassar os recursos do Salário-Educação de forma organizada, e não como vem sendo feito hoje. Este ano recebemos $\operatorname{Cr} \$ 500$ milhões em um mês, outros 500 milhöes no mês seguinte e finalmente 3,5 bilhões, em vez de prestações regulares de 1,5 bilhões. Se esses recursos fossem transferidos em um fluxo programado, poderíamos planejar melhor a sua utilização. Além disso, estamos recebendo menos do que deveríamos.

Resumindo, formulamos o seguinte raciocínio: em primeiro lugar, procuramos saber qual o compromisso mínimo a ser assumido com os alunos, pais, professores e demais profissionais do ensino no que diz respeito à escola è à educação. Enfatizamos que o nosso plano de ação não tem nada de fantástico ou de original pois consta das próprias obrigações estabelecidas pela Constituição. O nosso compromisso é, portanto, o de trabalhar para fazer a Constituição tornar-se realidade. Para tanto, estabelecemos cinco prioridades: (1) autonomia da escola; (2) fortalecimento da direção da escola - da diretora e do Colegiado; (3) aperfeiçoamento e capacitação de professores; (4) avaliação do Sistema; (5) integração com o Município. Essas cinco prioridades se desdobram em mais de cem planos, alguns deles em andamento.

A maioria das pessoas que estão aqui é do ramo e sabe que em educação os resultados não são visiveis de imediato. As mudanças não são observadas no dia-a-dia mas no ano-a-ano. É um processo lento, demorado. Investir em educação de qualidade é, porém, o único caminho para a cidadania e o único passaporte para o primeiro mundo. Nosso plano de ação é um plano para fazer, para agir, e apresenta a simplicidade demonstrada. Está à disposição para ser discutido, criticado e melhorado. Vamos monitorá-lo com tranqüilidade e objetividade pois não somos os donos da verdade. Periodicamente a Secretaria da Educação se reunirá para analisar o que está e o que não está dando certo. Temos, porém, orgulho de poder mostrar-lhes um plano concreto em andamento, que busca a melhoria da Educação em Minas Gerais. 